\title{
Die Pforten der Träume und der prophetische Flug der Seele: ein klassisches literarisches Thema bei J.L. Borges
}

\author{
The Gates of Dreams and the Prophetic Flight of the Soul: \\ a Classical Literary Theme in J.L. Borges
}

DAVID HERNÁNDEZ DE LA FUENTE*

\begin{abstract}
This paper deals with a literary leitmotiv from the Graeco-Roman Classical Tradition in the works of Jorge Luis Borges, with special emphasis on his poetry. The theme of the Gates of Dreams and of the soul that, after loosing its ties from the body while the latter sleeps, flies freely and comes back afterwards with a prophetic knowledge, appears often in Classical Antiquity, both in poetry and philosophy. Perhaps the best know example is a passage in the Odyssey in which Penelope warns Odysseus about the difference between false dreams and prophetic dreams. Virgil's Aeneid contains another reworking of this issue, which is treated by thinkers such as Plato and Cicero. This double role of dreams, both as prophecies and as sources for literary inspiration, was known to Borges, who theorizes about it in some of his essays. But, more interestingly, one can find literary traces of this theme in some of Borges' most famous poems.
\end{abstract}

\begin{abstract}
Resumen: Este artículo trata de un leitmotiv literario de la tradición clásica grecolatina en la obra de Jorge Luis Borges, con especial énfasis en su poesía. El tema de las puertas de los sueños y del alma que, después de haber disuelto sus lazos con el cuerpo o mientras este duerme, vuela libremente y vuelve después con un conocimiento profético, aparece a menudo en la Antigüedad clásica, tanto en la poesía como en la filosofía. Tal vez el mejor ejemplo es un pasaje de la Odisea en el que Penélope advierte a Ulises sobre la diferencia entre los falsos sueños y los sueños proféticos. La Eneida de Virgilio contiene una reelaboración de este motivo, cuyo tratamiento filosófico puede verse en pensadores como Platón y Cicerón. Este doble papel de los sueños, bien como profecías o bien fuente de inspiración literaria, era conocido por Borges, que teoriza acerca de ello en algunos de sus ensayos. Sin embargo, y tal vez lo más interesante, se pueden encontrar huellas literarias de este tema en algunos de los poemas más famosos de Borges.
\end{abstract}

Fecha de recepción: 11/06/2016. Fecha de aceptación: 20/07/2016.

* Professor für Altertumswissenschaft an der Nationalen Fernuniversität Spaniens (UNED). Email: dhdelafuente@ geo.uned.es. Forschungsinteressen: Kulturgeschichte der Antike, Griechische Literatur und Gesellschaft der römischen Kaiserzeit (bes. Nonnos), Griechische Religion (bes. Mantik und Dionysismus), Geschichte der Platonismus (bes. Platons Gesetze). Letzte Buch-Publikationen: Historia del Pensamiento Político griego (mit Pedro Barceló), Madrid: Trotta 2014 und Mitología griega, Madrid: Alianza 2015. Die Überlegungen zu diesem Beitrag entstanden während meines Aufenthaltes als Stipendiat der Humboldt-Stiftung an der Universität Potsdam im Jahr 2010. Er ist Rocío Orsi in memoriam gewidmet. 
„Und die Seele unbewacht, will in freien Flügen schweben, um im Zauberkreis der Nacht tief und tausendfach zu leben." H. Hesse

\section{Die Pforten der Träume}

Das Thema der Pforten der Träume und der Seele, die im Schlaf fliegt, um unerforschte Ebenen der Realität zu besuchen und eine metaphysische und manchmal auch prophetische Erkenntnis zu gewinnen erscheint in den Werken einiger wichtiger Autoren der griechischen und römischen Philosophie, wie Platon und Cicero ${ }^{1}$. Dieses Thema war tief in der griechischrömischen Poesie und besonders in zwei bekannten Passagen der Odyssee und der Aeneis verwurzelt. Gemäß der klassischen Überlieferung gab es zwei mythologische Tore zu den Träumen, welche den Menschen Visionen und Vorhersagen auf verschiedene Weise mitteilten. So erklärt Penelope, die Odysseus noch nicht erkannt hat, nachdem dieser versucht hatte, einen ihrer Träume zu deuten (Odyssee XIX 560ff.):

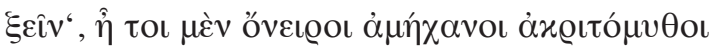

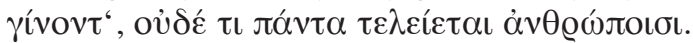

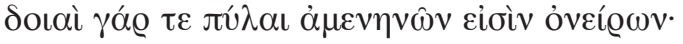

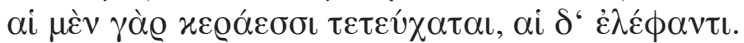

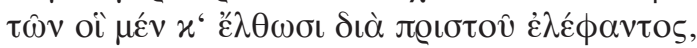

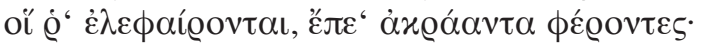

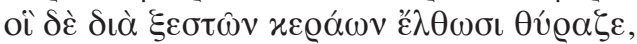

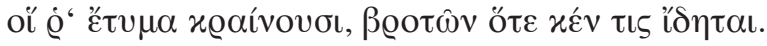

Fremdling, es gibt doch dunkle und unerklärbare Träume,

Und nicht alle verkünden der Menschen künftiges Schicksal.

Denn es sind, wie man sagt, zwei Pforten der nichtigen Träume:

Eine von Elfenbein, die andre von Horne gebauet.

Welche nun aus der Pforte von Elfenbeine herausgehn,

Diese täuschen den Geist durch lügenhafte Verkündung;

Andere, die aus der Pforte von glattem Horne hervorgehn,

Deuten Wirklichkeit an, wenn sie den Menschen erscheinen².

Träume können dementsprechend in zwei Kategorien unterschieden werden: einerseits die Prophezeiungen, welche die Götter den Sterblichen durch die Gabe des Schlafes vermitteln. Zu dieser erste Kategorie behauptet Cicero, dass die Träume eine Art ,natürliche Wahrsagung“ („quod arte careret“, De div. I 18) verkörpern. Aber andererseits gibt es Träume,

1 Plat. Tim. 71b, Cic. De div. I 4.

2 Ilias und Odyssee, In der Übertragung von Johann Heinrich Voß; nach dem Text der Erstausgabe (Ilias: Hamburg 1793, Odyssee:, Hamburg 1781) mit einem Nachwort von W.H. Friedrich. Stuttgart / Hamburg (Dt. Bücherbund) o.J. 
die nicht mehr als bloße Erfindungen und lügnerische Phantasien sind. Diese treten in einem irrealen Gebiet auf und haben vielleicht stärker eine literarische Bedeutung.

Ein literarisches Nachleben dieses Themas kann man im Werk Jorge Luis Borges finden. Die Verwendung der Träume ist eines der eigentümlichsten Merkmale seines Werkes. Unabhängig von der freudschen Traumdeutung ist dieses Motiv bei Borges von der klassischen Tradition inspiriert, sowohl poetisch als auch philosophisch. In Borges Werk treffen beide Arten der Fiktion aufeinander. Meines Erachtens spielt die Metapher der Tore der Träume eine Schlüsselrolle in der literaturwissenschaftlichen und philosophischen Traumdeutung des argentinischen Autors. In diesem Sinne werden die folgende Anmerkungen die Rezeption dieses Leitmotivs in Borges Werk und insbesondere in seiner Dichtkunst unterstreichen.

Borges nahm die Wichtigkeit des Begriffes schon in der Odyssee wahr, die er nicht in ihrer originalen griechischen Sprache, sondern in einer der englischen Übersetzungen las ${ }^{3}$. So kannte er beispielsweise besonders gut die Prosa-Version von Samuel Butler.

Stranger, dreams are very curious and unaccountable things, and they do not by any means invariably come true. There are two gates through which these insubstantial fancies proceed; the one is of horn, and the other ivory. Those that come through the gate of ivory are fatuous, but those from the gate of horn mean something to those that see them ${ }^{4}$.

Obwohl die Vorliebe für Homer angesichts seiner 65 Erwähnungen in Borges Werk offensichtlich ist, erscheint Vergil als Hauptquelle dieses Themas beim Argentinier. Die Aeneis greift das Motiv dieser mythischen Tore am Ende des sechsten Buches auf und stellt die Träume beider Arten auf folgende Weise vor (Aeneis VI 893 ff.):

Sunt geminae Somni portae, quarum altera fertur

cornea, qua veris facilis datur exitus umbris;

altera candenti perfecta nitens elephanto,

sed falsa ad caelum mittunt insomnia Manes.

Träume benutzen zum Austritt zwei Tore. Das eine besteht aus

Horn, ihm entschlüpfen mit Leichtigkeit die tatsächlichen Schatten;

aus hellschimmerndem Elfenbein wurde das andre gestaltet,

dadurch entlassen die Manen nur täuschende Träume zum Himmel ${ }^{5}$.

3 García Gual, C. «Borges y los clásicos de Grecia y Roma», Cuadernos hispanoamericanos, № 505-507, 1992 (Homenaje a Jorge Luis Borges), 321-346, insbesondere S. 322, An. 3. In «Acerca de mis cuentos» schreibt Borges: «Lo vemos en la primera línea -yo no sé griego- de la Iliada de Homero, que leemos en la versión tan censurada de Hermosilla: „Canta, Musa, la cólera de Aquiles“.»

4 The Iliad of Homer and the Odyssey / rendered into English prose by Samuel Butler, Encyclopaedia Britannica, Chicago [etc.], 1987.

5 Vergil: Werke in einem Band. Herausgegeben und aus dem Lateinischen übersetzt von Dietrich Ebener. 2. Auflage. Aufbau-Verlag, Berlin, 1987. 
Borges las die englische Version der Aeneis von John Dryden, der diese Stelle so übersetzt:

Two gates the silent house of Sleep adorn;

Of polish'd ivory this, that of transparent horn:

True visions thro" transparent horn arise;

Thro‘ polish'd ivory pass deluding lies ${ }^{6}$.

Das elfenbeinerne Tor stellt zweifellos eine grobe Verfälschung der Wirklichkeit dar, und vielleicht deshalb wurde es am häufigsten von Dichtern und Schriftstellern ufgegriffen / verwendet. Borges war sich dessen sehr wohl bewusst, wie man auch im Vorwort zu Libro de Sueños lesen kann ${ }^{7}$. Dort fügt der argentinische Schriftsteller zu seiner literarischen Sammlung von Träumen und Visionen die folgende Zusammenfassung der vergilischen Episode hinzu:

El sexto libro de la Eneida sigue una tradición de la Odisea y declara que son dos las puertas divinas por las que nos llegan los sueños: la de marfil, que es la de los sueños falaces y la de cuerno, que es la de los sueños proféticos. Dados los materiales elegidos, diríase que el poeta ha sentido de una manera oscura que los sueños que se anticipan al porvenir son menos preciosos que los falaces, que son una espontánea invención del hombre que duerme.

In einem weniger bekannten Text unter dem Titel "Noche segunda: la pesadilla", der zum Sammelband Siete Noches seiner Vorträge im Theater Coliseo de Buenos Aires gehört ${ }^{8}$, stellt Borges die Frage der prophetische Träume in einem detaillierten Bericht vor:

Hay otro tema que no puede eludirse: los sueños proféticos. Es propia de una mentalidad avanzada la idea de los sueños que corresponden a la realidad, ya que hoy distinguimos los dos planos.

Hay un pasaje en la Odisea en el que se habla de dos puertas, la de cuerno y la de marfil. Por la de marfil llegan a los hombres los sueños falsos y por la de cuerno, los sueños verdaderos o proféticos. Y hay un pasaje en la Eneida (un pasaje que ha provocado innumerables comentarios): en el libro noveno, o en el undécimo, no estoy seguro, Eneas desciende a los Campos Elíseos, más allá de las Columnas de Hércules: conversa con las grandes sombras de Aquiles, de Tiresias; ve la sombra de su madre, quiere abrazarla pero no puede porque está hecha de sombra; y ve, además, la futura grandeza de la ciudad que él fundará. Ve a Rómulo, a Remo, el campo y, en ese campo, ve al futuro Foro Romano, la futura grandeza de Roma, la grandeza de Augusto, ve toda la grandeza imperial. Y después de haber visto todo eso, después de haber conversado con sus contemporáneos, que son gente futura para

6 Aus Virgil's Aeneid / translated by John Dryden with introduction and notes, P. F. Collier, New York, 1965.

7 Borges, J.L., Libro de sueños, Alianza, Madrid, 2002.

8 Erste Ausgabe von 1980. Dazu J.L. Borges, Siete noches, Alianza, Madrid, 1999. Cf. auch J.L. Borges, Obras completas, tomo III, Emecé, Buenos Aires, 2000. 
Eneas, Eneas vuelve a la tierra. Entonces ocurre lo curioso, lo que no ha sido bien explicado, salvo por un comentador anónimo que creo que ha dado con la verdad. Eneas vuelve por la puerta de marfil y no por la de cuerno. ¿Por qué? El comentador nos dice por qué: porque realmente no estamos en la realidad. Para Virgilio, el mundo verdadero era posiblemente el mundo platónico, el mundo de los arquetipos. Eneas pasa por la puerta de marfil porque entra en el mundo de los sueños - es decir, en lo que llamamos vigilia.

Bueno, todo esto puede ser.

In dieser etwas längeren Paraphrase Vergils spiegelt sich spürbar die Leidenschaft des argentinischen Autors für das lateinische Epos wieder. Etwa 56 Zitate und mehrere Anspielungen in Borges Werken beweisen die Bewunderung für den römischen Dichter, die in einem kürzlich erschienenen Buch unter dem Titel Borges autor de la Eneida von Francisco García Jurado ${ }^{9}$ dargelegt wurde.

Aber in Bezug auf Träume ist es offensichtlich, dass Borges den Traum, der zwar plausible aber falsche Vorstellungen inspiriert, als attraktiver empfindet. Durch diese Träume kann der Dichter einen Rahmen schaffen, in welchen seine Leser integriert sind. Genau das ist die Wirkung seiner Literatur und die bewusste und methodische Verwendung dieser Art von Traum ist sozusagen das Haupterbe dieses Themas in Borges' Gedichten und Erzählungen.

\section{Die Pforte aus Elfenbein}

Das interessanteste der literarischen Materialien wird dann durch das Tor der falschen Träume übergeben. Im Gedicht "La cierva blanca” („Der weiße Hirsch“)10 evoziert Borges diese Auffassung vom Traum.

¿De qué agreste balada de la verde Inglaterra, de qué lámina persa, de qué región arcana de las noches y días que nuestro ayer encierra, vino la cierva blanca que soñé esta mañana?

Duraría un segundo. La vi cruzar el prado y perderse en el oro de una tarde ilusoria, leve criatura hecha de un poco de memoria y de un poco de olvido, cierva de un solo lado.

Los númenes que rigen este curioso mundo me dejaron soñarte, pero no ser tu dueño; tal vez en un recodo del porvenir profundo

9 García Jurado, F., Borges autor de la Eneida, ELR, Madrid, 2006.

10 Erste Ausgabe in der literarischen Abteilung der Zeitung La Nación, 22.06.1975. Später in La rosa profunda (1975). Alle Referenzen zu Borges Dichtung beziehen sich auf die Ausgabe Obra poética 1923-1976. Alianza Tres/Emecé, Madrid,1979. 
te encontraré de nuevo, cierva blanca de un sueño.

Yo también soy un sueño lúcido que perdura

un tiempo más que el sueño del prado y la blancura.

Nochmals ist das Wachsein ein Traum und die Träume zeigen eine andere literarische Dimension. Dichter und Leser sind in einer einzigen Welt verwirrt und in nebulösen Regionen zwischen Realität und Fiktion vereint. In diesem Zusammenhang gelten der weiße Hirsch und seine legendäre Herkunft als Symbole der literarischen Prägung seiner schwer fassbaren Literatur. In diesem Gedicht erscheint der Traum wie bei Calderon als ein mit dem Leser besonders verbundenes Kontinuum von Literatur und Leben, das Borges' Schreiben dauerhaft inspirierte. Ein anderes Beispiel dieses dichterischen Wissens ist "Arte poética" ("Dichtkunst"), das zum Buch El hacedor (1960) gehört ${ }^{11}$. Die letzten vier Verse lauten dort:

Sentir que la vigilia es otro sueño que sueña no soñar y que la muerte que teme nuestra carne es esa muerte de cada noche, que se llama sueño.

Bemerkenswert an diesem Vierzeiler ist, dass die Zuordnung des Todes zum Traum -,,esa muerte de cada noche“- einer Tradition folgt, die sich bis zu Hesiods Theogonie zurückführen lässt (756): „Schlaf, Bruder des Todes“. Etwas später im gleichen, berühmten Gedicht, realisiert Borges die enge, innige Verbindung zwischen Tod und Traum gemäß der klassischen Überlieferung: "Ver en la muerte el sueño, en el ocaso / un triste oro."

Aber die Pforte aus Elfenbein steht auch für eine bestimmte Art von Träumen, die eine wichtige Rolle in der Literatur Borges spielen: die Alpträume. Die unangenehmen Alpträume faszinieren unseren Autor als Quelle der literarischen Schöpfung. Wieder im Libro de sueños spricht Borges zunächst in folgender Weise:

Hay un tipo de sueño que merece nuestra singular atención. Me refiero a la pesadilla, que lleva en inglés el nombre de nightmare o "yegua de la noche", voz que sugirió a Victor Hugo la metáfora de cheval noir de la nuit, pero que, según los etimólogos, equivale a ficción o fábula de la noche. Alp, su nombre alemán, alude al elfo o íncubo que oprime al soñador y que le impone horrendas imágenes. Ephialtes, que es el término griego, procede de una superstición análoga.

Angesichts der Auswirkungen solcher Träume in der Literatur wurden die bedeutendsten Etymologien dieses Begriffes in verschiedenen Sprachen in "Noche segunda: la pesadilla" von Borges wiederum zusammengefasst.

El nombre español no es demasiado venturoso: el diminutivo parece quitarle fuerza. En otras lenguas los nombres son más fuertes. En griego la palabra es ephialtes: Ephialtes es el demonio que inspira la pesadilla. En latín tenemos el incubus. El

11 Borges, J.L., El hacedor. Alianza, Madrid, 2005. 
íncubo es el demonio que oprime al durmiente y le inspira la pesadilla. En alemán tenemos una palabra muy curiosa: Alp, que vendría a significar el elfo y la opresión del elfo, la misma idea de un demonio que inspira la pesadilla. [...] Llegamos ahora a la palabra más sabia y ambigua, el nombre inglés de la pesadilla: the nightmare, que significa para nosotros "la yegua de la noche". Shakespeare la entendió así. Hay un verso suyo que dice "I met the night mare", "me encontré con la yegua de la noche". Se ve que la concibe como una yegua. Hay otro poema que ya dice deliberadamente "the nightmare and her nine foals", "la pesadilla y sus nueve potrillos", donde la ve como una yegua también.

Pero según los etimólogos la raíz es distinta. La raíz sería niht mare o niht maere, el demonio de la noche.

Besonders interessant ist, dass sowohl die falsche bzw. populäre Etymologie des englischen Nightmare (,Stute der Nacht“) als auch der wahre Ursprung des Wortes („Fiktion oder Märchen der Nacht“) als „la palabra más sabia y ambigua“ betont werden, sodass der Leser hier die Quelle von Borges literarischer Verwendung solcher Träume klarer erkennen kann. Es wirdzunächst erwähnt, dass die deutsche Etymologie von Alptraum viel mit der klassischen Figur des Incubus, aber auch mit der germanischen Mythologie zu tun hat. Die „Alben“ oder „Nachtalben“ waren eine bestimmte Art von Sagenwesen oder Elfen der Träume. Diese hießen ursprünglich „Mahren“ oder „Nachtmahren“ und verweilten in der Nacht auf der Brust der Schlafenden und flößten ihnen Grauen ein. In diesem Bezug bezieht sich Borges des Weiteren auf die europäische Romantik durch eine Erwähnung des berühmten romantischen Gemäldes Nachtmahr (1802) von J. H. Füssli, das sich heute im Detroit Institute of Fine Arts befindet und ein solches Wesen zeigt (s. unten).

In diesem Sinne scheint das folgende Sonett, "La pesadilla" ${ }^{2}$, fast nach einem Diktat eines solchen Elfen geschrieben oder zumindest von der keltischen Dichtkunst des W.B. Yeats inspiriert.

Sueño con un antiguo rey. De hierro es la corona y muerta la mirada.

Ya no hay caras así. La firme espada lo acatará, leal como su perro.

No sé si es de Nortumbria o de Noruega.

Sé que es del Norte. La cerrada y roja barba le cubre el pecho. No me arroja una mirada su mirada ciega.

¿De qué apagado espejo, de qué nave de los mares que fueron su aventura, habrá surgido el hombre gris y grave

12 In La moneda de hierro (1976). 


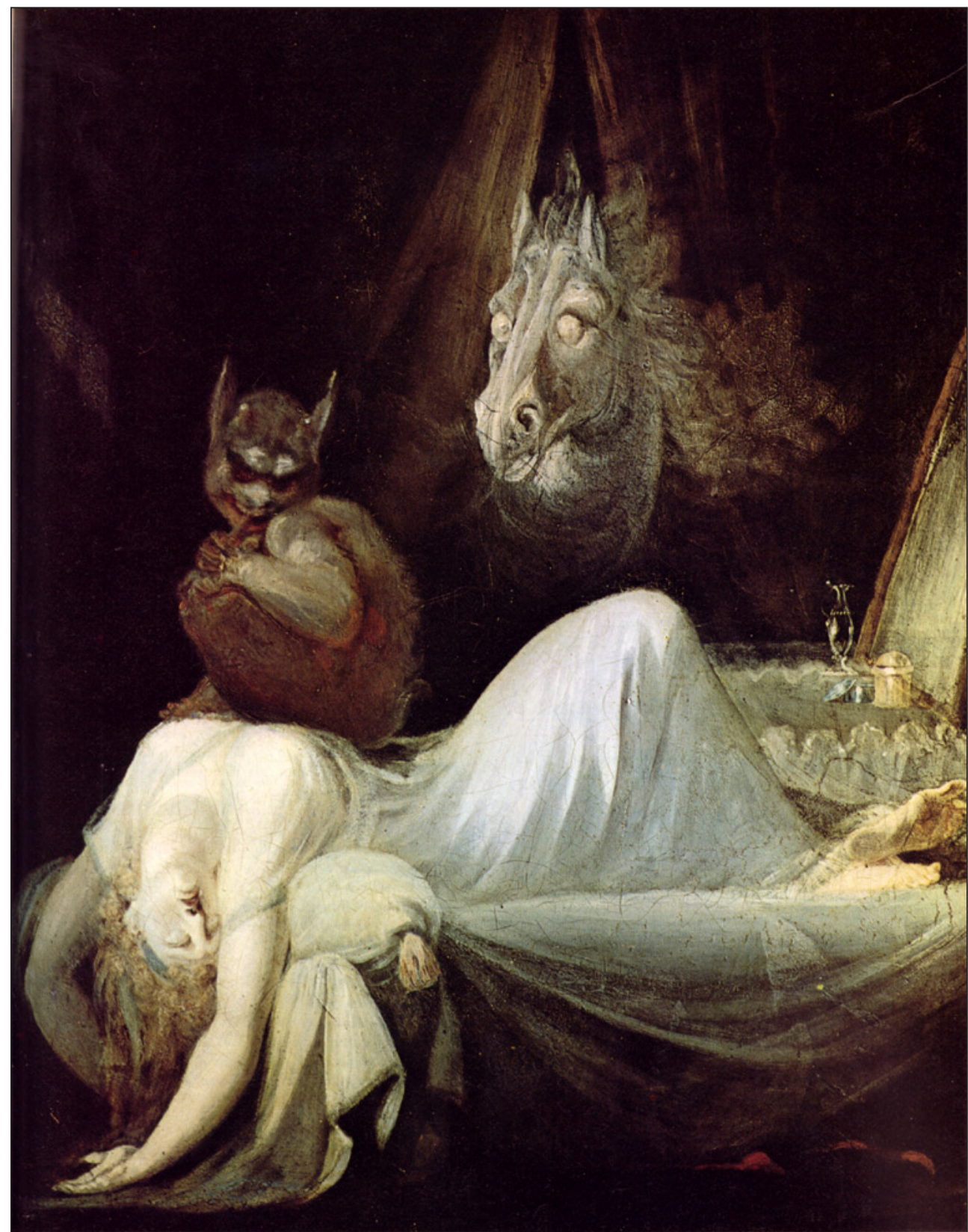

que me impone su antaño y su amargura?

Sé que me sueña y que me juzga, erguido. El día entra en la noche. No se ha ido. 
Etwas später möchte Borges seine persönlichen Alpträume in einer luziden literarischen Übung klassifizieren. Der Autor nennt zwei Arten von Alpträumen "que pueden llegar a confundirse" und die sehr nützlich für das Verständnis einiger seiner bekanntesten Erzählungen und Gedichte scheinen. Die erste Art ist der Schrecken des Labyrinths, den er in seiner Kindheit durch eine alte Zeichnung des Labyrinths von Kreta in einem Buch über die sieben Weltwunder vernahm. Natürlich kann man an die Geschichte „La Casa de Asterión“ denken, welche den Mythos des Minotaurs erzählt. Die zweite Art Alptraum betrifft das Problem der Identität und der Widerspiegelungen des Selbst und des Anderen: es ist der Traum des Spiegels, der häufig Thema seines Werkes ist, wie beispielsweise als Herkunft des skandinavisches Königs im Gedicht „La pesadilla“. Ich zitiere erneut aus “Noche segunda: la pesadilla", im Siete Noches:

Siempre sueño con laberintos o con espejos. En el sueño del espejo aparece otra visión, otro terror de mis noches, que es la idea de las máscaras. Siempre las máscaras me dieron miedo. Sin duda sentí en la infancia que si alguien usaba una máscara estaba ocultando algo horrible. A veces (éstas son mis pesadillas más terribles) me veo reflejado en un espejo, pero me veo reflejado con una máscara. Tengo miedo de arrancar la máscara porque tengo miedo de ver mi verdadero rostro, que imagino atroz. Ahí puede estar la lepra o el mal o algo más terrible que cualquier imaginación mía.

Auf diese Alpträume wirkt natürlich der Einfluss der griechisch-römischen Literatur, die sich kontinuierlich mit keltischen und germanischen Themen vermischt. Die Kombination aus der Wiederauferstehung dieses klassischen Themas und fantastischen Märchen der Romantik muss als metaliterarisches Instrument in der großen Tradition der europäischen Traum-Literatur berücksichtigt werden. Die Themen Borges‘ wie Identitätsproblematik, Doppelgänger, das Leben als Traum, Metafiktion oder phantastische Elemente im Alltagsleben stammen zweifellos aus der Vermischung der klassischen, also homerischen und vergilianischen Tradition mit der späteren Fantastik. In diesem Zusammenhang lohnt es sich, den Ausspruch Gerard de Nervals aus dem Beginn seiner Aurélia zu erwähnen: "Le Rêve est une seconde vie. Je n'ai pu percer sans frémir ces portes d'ivoire ou de corne qui nous séparent du monde invisible"13.

\section{Die Pforte aus Horn}

«Wir sind dem Aufwachen nah, wenn wir träumen, daß wir träumen» ${ }^{14}$, wie Novalis schreibt. Und gerade dieses Gefühl bezeichnet die zweite Art von Traum bei Borges. Der Begriff prophetischer Träume spielt auch eine bedeutende Rolle als literarische Methode; insbesondere in seiner Erzählkunst. Zwischen der Realität und den Träumen gibt es die Prophezeiung als Verschmelzung beider Elemente, die nämlich einem vermittelnden Momentum zwischen der klassischen Welt und der europäischen Romantik basiert. Die spanische Lite-

13 Nerval, G., de Les filles du feu : Aurélia; postface et notes de Francine de Martinoi Seuil, Paris, 1992

14 Novalis, Werke, hrsg. von G. Schulz, C.H. Beck, München, 1969, S. 326. 
ratur aus dem sogenannten Goldenen Zeitalter ist ein Schlüsselelement in der Überlieferung des Themas traumhafter Wahrsagung bei Borges.

Die europäische Neuzeit hat das Thema der Pforten der Träume durch die Klassifizierung und Zusammenfassung des Macrobius in der Spätantike gekannt ${ }^{15}$. Überall finden wir Echos dieses Motivs bei den spanischen Autoren, wie Garcilaso, der in seiner Égloga II. 113-118 schreibt:

¿Es esto sueño, o ciertamente toco

la blanca mano? ¡Ah sueño! ¿estás burlando?

Yo estábate creyendo como loco.

¡Oh cuitado de mí! Tú vas volando

con prestas alas por la ebúrnea puerta;

yo quédome tendido aquí llorando ${ }^{16}$.

Der prophetische Traum scheint schon in Cervantes Don Quixote sowohl die definitive Grenze der Fiktion als auch ein literarisches Erbe des Altertums zu sein. In einem Buch von 1994 untersuchte Aurora Egido die Episoden der traumhaften Inspiration bei Cervantes. ${ }^{17}$ Gute Beispiele hierfür sind der so genannte Retablo des Maese Pedro (Don Quixote, 2. Teil) und vor allem der Abstieg in die Höhle von Montesinos, eine Art katabasis in die Unterwelt mit den zugehörigen Visionen "parte... falsas y parte verisímiles" (2. Teil, Kap. XXV). ${ }^{18}$

Zwei andere wichtige Autoren des spanischen Barock dienen auch als Vermittler für die Beschäftigung mit diesem Begriff. Auf der einen Seite betonte Quevedo mit einem Zitat Homers, wie nützlich für den Schriftsteller das göttliche Vorrecht der prophetischen Träume ist. Das entsprechende Zitat am Anfang seines ersten Sueño lautet: "Los sueños, Señor, dice Homero que son de Júpiter y que él los envía; y en otro lugar dice que se ha de creer que esto es así cuando tocan en cosas importantes o los sueñan Reyes o grandes señores"19.

Calderón de la Barca ist die zweite barocke Quelle der Traumdeutung Borges. Der Argentinier verteidigt die Wichtigkeit der poetischen Intuition für eine echte literarische Verwendung der Träume, unabhängig von der Art und Weise freudscher Interpretationen. Die duale Taxonomie Homers zeigt sich gemäß Borges in der Poesie - vielmehr als in der Psychologie -, wo die tiefen und intuitiven Wahrheiten der Literatur als Träume kategorisiert werden. Das folgende Zitat von "Noche segunda: la pesadilla" enthält einige Zeilen aus Calderóns Sonnett "A un sueño":

Como quiera que sea, en las pesadillas lo importante no son las imágenes. Lo importante, como Coleridge — decididamente estoy citando a los poetas - descubrió, es la

15 Cf. Stahl, W.H., Macrobius. Commentary on the Dream of Scipio, Columbia University, New York 1990.

16 Zum Text und dem klassischen Kommentar von Fernando de Herrera, cf. Gallego Morell, A. (Hrsg). Garcilaso de la Vega y sus comentaristas, Gredos, Madrid 1972.

$17 \mathrm{Zu}$ dieser Tradition bei Cervantes, cf. Egido, A.,Cervantes y las puertas del sueño. Estudios sobre «La Galatea», «El Quijote»y «El Persiles». PPU, Barcelona, 1994, S. 137-178.

18 Riva, R., «La cueva de Montesinos como oráculo», Revue Romane 42.2, 2007, S. 334-344, analysiert diese Episode im Vergleich mit den uralten griechischen Orakeln der Träume und mit der mythischen las katábaseis (Abfährte) von klassischen Helden. Für diese Abfahrt als Traum-Metapher cf. Egido (loc. cit.).

19 Cf. die Ausgabe von Arellano, I., Francisco de Quevedo, Los sueños, Cátedra, Madrid, 1991. 
impresión que producen los sueños. Las imágenes son lo de menos, son efectos. Ya dije al principio que había leído muchos tratados de psicología en los que no encontré textos de poetas, que son singularmente iluminativos ${ }^{20}$. Veamos uno de Petronio. Una línea de Petronio citada por Addison. Dice que el alma, cuando está libre de la carga del cuerpo, juega. "El alma, sin el cuerpo, juega." Por su parte, Góngora, en un soneto, expresa con exactitud la idea de que los sueños y la pesadilla, desde luego, son ficciones, son creaciones literarias:

El sueño, autor de representaciones,

en su teatro sobre el viento armado

sombras suele vestir de bulto bello ${ }^{21}$.

Im Falle Calderóns gibt es prophetische Träume von Königen oder Potentaten wie Henry VIII von England oder Salomon in den Stücken El cisma de Ingalaterra (143) und La Sibila del Oriente (1156). Im letztgenannten Werk wurde Gottes Besuch bei Salomon in dessen Traum so beschrieben:

Suena música, córrese una cortina y debajo de un dosel aparece Salomón durmiendo, vestido a lo romano y por lo alto, en una apariencia, sale una visión, cantando, cubierto el rostro.

Salomón: Dios grande, inmenso Señor,

¿Vos a visitarme a mí ?

¿Vos a vuestro esclavo hacéis

tan grandes favores?

Dios: $\quad$ Sí.

$[\ldots]$

Pide y espera de mí mercedes; que yo concedo cuanto me quieras pedir.

Sal. Grande Dios de las batallas, Pues hoy cargas sobre mí Todo el peso de tu pueblo. Porque mi humilde cerviz No desmaye, dame ciencias Con que me pueda regir.

20 Am Anfang dieses Textes schreibt Borges eine offensichtliche Referenz zu Freud: «Estuve releyendo estos días libros de psicología. Me sentí singularmente defraudado. En todos ellos se hablaba de los instrumentos o de los temas de los sueños (voy a poder justificar esta palabra más adelante) y no se hablaba, lo que yo hubiera deseado, sobre lo asombroso, lo extraño del hecho de soñar.» Wichtig erscheint hier, dass Borges eine Vorliebe für die antike Traumdeutung im Bezug zu freudscher Psychoanalyse zeigt. Zur Bedeutung der Psychoanalyse in Argentinien, cf. Plotkin, M., «The Diffusion of Psychoanalysis in Argentina«, Latin American Research Review, Vol. 33, N. 2, 1998, S. 271-277.

21 Ciplijauskaité, B. (Hrsg.), Luis de Góngora, Sonetos completos, Castalia, Madrid, 1969, S. 130. 
Dios: $\quad$ Justa fue tu petición;

yo la concedo.

Bemerkenswert ist auch dieses Thema in der Erzählkunst Borges ' und besonders passend scheint hier die Erzählung El milagro secreto (1943) nach dem Vorbild Calderóns. Der Protagonist dieser Geschichte, die während des Zweiten Weltkriegs geschrieben wurde, ist ein tschechischer Schriftsteller namens Jaromir Hladik. Hladik arbeitet immerzu an seinem unvollendeten Stück Los enemigos und bekommt bedeutende Träume aus den doppelten Pforten des Mythos. Sein erster Traum enthält die prophetische Vision eines ewigen Schachspiels, an dem er teilnimmt und die Vorhersage seines eigenen Todes durch die Hände der Nationalsozialisten, die Prag besetzen. Nach seinem Todesurteil träumt der Schriftsteller wieder und dieses Mal ist sein Traum literarisch und wunderbar, wie der Titel der Erzählung andeutet. Hladik erhält eine sozusagen göttliche Eingebung im Schlaf wie in der klassischen Überlieferung. Der Schriftsteller beginnt ein Gespräch mit der Gottheit und bittet diese:

Si de algún modo existo, si no soy una de tus repeticiones y erratas, existo como autor de Los enemigos. Para llevar a término ese drama, que puede justificarme y justificarte, requiero un año más. Otórgame esos días, Tú de quien son los siglos y el tiempo.

Nach dem Hören einer "allgegenwärtigen" Stimme, welche die Vollkommenheit der Wunder bestätigt, gewährt die Gottheit dem Schriftsteller ein Jahr, um seine Arbeit zu vollenden. Aber in der realen Welt dauert dieses Jahr nur eine Minute, während Hladik vom Erschießungskommando hingerichtet wird.

Dass der prophetische Traum ein außergewöhnliches Zeitmaß darstellt, erfuhr Quevedo nach seinem Abstieg in die Unterwelt, den er detailliert am Ende des Sueño de la mиerte beschreibt. Quevedo erschreckt sich in seinem Bett "como si la pendencia hubiera sido verdad y la peregrinación no hubiera sido sueño". Also beschließt Quevedo "no despreciar del todo esta visión y darle algún crédito, pareciéndome que los muertos pocas veces se burlan, y que gente sin pretensión y desengañada, más atiende a enseñar que a entretener". Beim Erwachen kann der Schriftsteller aus den Regionen jenseits des Traumes eine wichtige Lektion weitergeben.

\section{Fazit: eine Poetik der Träume}

Letztlich ist die Identifikation des Autors mit dem Charakter ein wesentliches Leitmotiv abgeleitet von dieser doppelten literarischen Verwendung der Träume und ihrer zwei Pforten. Unser s Beispiel eines dichterischen Traumes bei Borges ist ein Cervantes und Don Quixote gewidmetes Sonett unter dem Titel "Sueña Alonso Quijano” („Alonso Quijano träumt"). Hier verbindet Borges das klassische Thema der Pforten der Träume mit diesen erwähnten Episoden von Don Quixote, wie der Begriff "el doble sueño" andeutet. Auch hier wurde Cervantes von Don Quixote geträumt, wie Borges vom skandinavischen König im Sonett „La pesadilla“. 
El hombre se despierta de un incierto sueño de alfanjes y de campo llano y se toca la barba con la mano y se pregunta si está herido o muerto.

¿No lo perseguirán los hechiceros que han jurado su mal bajo la luna? Nada. Apenas el frío. Apenas una dolencia de sus años postrimeros.

El hidalgo fue un sueño de Cervantes y Don Quijote un sueño del hidalgo. El doble sueño los confunde y algo

está pasando que pasó mucho antes. Quijano duerme y sueña. Una batalla: Los mares de Lepanto y la metralla.

In dieser Poetik der Träume nähert sich Borges der endgültigen Erkenntnis an, die aus der Literatur der Antike kommt: Der Assimilation von Traum und Wachsein, Literatur und Leben. Irgendwo zwischen Wahrheit und literarischer Fälschung, Abenteuer und Traumdeutung liegt die Doppeltür des Traumes als Quelle aller Literatur. Durch das doppelte Tor träumt der Autor von seinen Charakteren und seine Charaktere träumen wiederum vom Autor. Beide vermischen sich in derselben nebulösen Welt des weißen Hirsches, des skandinavisches Königs, des tschechischen Schriftstellers; in einer Dimension, wo sich die Träume in greifbare Wirklichkeit verwandeln und die Realität zum sichtbaren Alptraum wird. Es war unsere Absicht, eine Klassifizierung der literarischen Verwendung der Träume bei Borges nach dem Beispiel der griechisch-römischen Literatur vorzunehmen und damit eine neue Perspektive auf beide Arten von Träumen in seinem Werk zu gewinnen. Das Thema der Pforten der Träume bei Borges erinnert uns an die subtile aber dauerhafte Beschäftigung mit dem ewigen Motiv der Traumdeutung, das sich als künstlerische Erfindung durch das Labyrinth der moderne Literatur zieht ${ }^{22}$.

\section{Literatur}

Arellano, Ignacio (Hrsg.) (1991): Francisco de Quevedo, Los sueños, Cátedra, Madrid. Borges, Jorge Luis (1979): Obra poética 1923-1976. Alianza Tres/Emecé, Madrid. Borges, Jorge Luis (1999): Siete noches. Alianza, Madrid.

Borges, Jorge Luis (2000): Obras completas, tomo III, Emecé, Buenos Aires.

Borges, Jorge Luis (2002): Libro de sueños, Alianza, Madrid.

Borges, Jorge Luis (2005): El hacedor, Alianza, Madrid.

22 Dazu im Allgemeinen vgl. Dieterle, B. (Hrsg.), Träumungen. Traumerzählung in Film und Literatur. Gardezi, St. Augustin, 1998. 
Ciplijauskaité, Biruté (Hrsg.) (1969), Luis de Góngora, Sonetos completos, Castalia, Madrid. Dieterle, Bernard (Hrsg.) (1998): Träumungen. Traumerzählung in Film und Literatur. Gardezi, St. Augustin.

Dryden, John (1965): Virgil's Aeneid / translated by John Dryden with introduction and notes, P. F. Collier, New York.

Ebener, Dietrich (Hrsg.) (1987): Vergil, Werke in einem Band. Herausgegeben und aus dem Lateinischen übersetzt von Dietrich Ebener. 2. Auflage. Aufbau-Verlag, Berlin.

Egido, Aurora (1994): Cervantes y las puertas del sueño. Estudios sobre «La Galatea», «El Quijote»y «El Persiles», PPU, Barcelona.

Gallego Morell, Antonio (Hrsg.) (1972). Garcilaso de la Vega y sus comentaristas, Gredos, Madrid.

García Gual, Carlos (1992): «Borges y los clásicos de Grecia y Roma», Cuadernos hispanoamericanos, $\mathrm{N}^{\circ}$ 505-507, (Homenaje a Jorge Luis Borges), 321-346

García Jurado, Francisco (2006): Borges autor de la Eneida, ELR, Madrid.

Nerval, Gerard de (1992): Les filles du feu : Aurélia; postface et notes de Francine de Martinoi, Seuil, Paris.

Novalis (1969): Werke, hrsg. von G. Schulz, C.H. Beck, München..

Plotkin, Mariano Ben (1998), «The Diffusion of Psychoanalysis in Argentina«, Latin American Research Review, Vol. 33, N. 2, 271-277.

Riva, Reynaldo (2007): «La cueva de Montesinos como oráculo», Revue Romane 42.2, 2007, 334-344.

Stahl, William Harris (Hrsg.) (1990): Macrobius. Commentary on the Dream of Scipio. Columbia University, New York. 